\title{
Amelioration of Physico-Chemical Parameters and Phytotoxicity of Landfill Leachate by Microbial Degradation
}

\author{
Tiham Z. A. Quraishi, Anuja A. Kenekar, Charu A. Fale, Prafull V. Ranadive and Ganesh R. Kamath* \\ Inventions and Innovations Department, Organica Biotech Pvt. Ltd, Govandi - 400088, Mumbai, Maharashtra, \\ India;Tiham@organicabiotech.com, Anuja@organicabiotech.com, Charu@organicabiotech.com, \\ Prafull@organicabiotech.com, r\&d@organicabiotech.com
}

\begin{abstract}
Objective: To understand the effect of microbial treatment on physico-chemical parameters and phytotoxicity of leachate arising from degradation of municipal solid waste. Methods and statistical Analysis: Landfill leachate samples were collected from a municipal landfill site in Mumbai, India at different phases of its degradation cycle. The leachate was subjected to anaerobic treatment using microbial consortium based product CleanMaxx ANB followed by its counterpart CleanMaxx for aerobic treatment. Post treatment, the physico-chemical properties were analysed and the phytotoxicity was assessed using seed germination assay. The results were interpreted using ANOVA. Findings: The physicochemical parameters of the old and fresh leachate samples were analyzed after biological treatment where the percentage COD reduction was $18.97 \%$ and $53.87 \%$; percentage ammoniacal nitrogen reduction was $22.78 \%$ and $58.8 \%$; percentage reduction in TDS was $24.8 \%$ and $34.76 \%$; percentage reduction in TSS was $24.05 \%$ and $23.5 \%$ and percentage colour reduction was $25.01 \%$ and $34.35 \%$ for old and fresh leachate respectively. The aging of landfill leachate sample may have reduced its biodegradable fraction with the increase in the concentration of high molecular compounds and highly toxic compounds, which may hinder with the microbial degradation process. The seed germination bioassay using Cicer arietinum (Bengal gram) seeds revealed that the percentage germination of seeds exposed to untreated leachate samples (both old and fresh) was 11.1 and $22.2 \%$ respectively $(\mathrm{p}<0.05)$. Microbial treatment of both these samples improved the germination percentage to $88.8 \%$ in both cases. Application/Improvements: The improvement in physicochemical properties and reduction in phytotoxicity indicates that the microbial remediation of landfill leachate could treat the top soils and groundwater tables at contaminated sites, making the surrounding land arable.
\end{abstract}

Keywords: Landfill, Leachate, Microbial Degradation, Phytotoxicity

\section{Introduction}

Currently, the most convenient and wide spread method employed for disposal of Municipal Solid Waste (MSW), is deposition in landfills. A landfill site is designed to prevent the waste degradation and dispersion of contaminants into the environment. The land filling method has drawbacks such as scarcity of available land, inefficient design, rapidly varying waste generation and characterization patterns due to growing population and industrial development in developing countries ${ }^{1}$. Unmanaged MSW becomes a factor for propagation of airborne, water borne and vector borne diseases ${ }^{2}$. Common problems at landfill sites are: air pollution due obnoxious odours from decomposing organic materials, occupational health hazards to workers in contact with the waste contaminants and its aerosols, contamination of soil and ground water due to leachate percolation ${ }^{3}$.

A by-product of the degradation of MSW is its leachate. Leachate is the liquid contaminant that seeps through the bottom of the solid waste disposal facilities such as landfills. It contains a variety of dissolved and suspended materials ${ }^{4}$. Major constituents of the leachate are complex organic substances, volatile fatty acids, xenobiotic organic 
chemicals, inorganic macro components and heavy metals. The composition of leachate varies widely depending on the composition of waste as well as the age of waste. Many phytotoxic compounds such as industrial solvents, agrochemicals, polymer pigments, filler materials from degraded plastic waste, halogenated hydrocarbons from refrigerants are common components of leachates ${ }^{5}$. The landfill site continues to produce leachate even after the municipal solid waste landfill site is closed. This process can last for 30-50 years which can have significant environmental impact if the leachate being produced is released untreated into the environment ${ }^{6}$.

It has been recognized that most trace elements and toxic compounds get fixed and accumulate in soil in an irreversible process, continuous influx of such chemical compounds in excess will eventually contaminate the soil, making it nonproductive for growth of plants. It has been established that degradation of such organic molecules with phytotoxic activity can be promoted by microbial treatment ${ }^{5}$.

Bioremediation is usually preceded by chemical or physical treatment methods such as flocculation, chemical precipitation, ammonium stripping, ion exchange, chemical oxidation etc ${ }^{7}$. The conventional biological methods in practice for treatment for leachate include anaerobic and aerobic degradation of organic load, removal of ammonium salts and de-nitrification. The treatment of huge landfills operated over long periods of time is usually carried out by anaerobic treatment ${ }^{8}$.

Anaerobic leachate treatment is an effective process, but when the remaining Biological Oxygen Demand (BOD) and Chemical Oxygen Demand (COD) effluent concentrations are high (COD > 1000- $4000 \mathrm{mg} / \mathrm{l})$ and $\mathrm{BOD} / \mathrm{COD}$-ratios $>0.3$, the anaerobic treatment step of the leachate has to be followed by means of aerobic processes to meet acceptable effluent standards ${ }^{8}$.

Post treatment of leachate, its physico-chemical properties and toxicity levels need to be evaluated to verify leachate quality. This is usually based on qualitative and quantitative analysis of chemicals. However, this data alone cannot reveal the overall toxic effects. Observations after several studies indicate that the groundwater near the landfill may be phytotoxic and can restrict algal growth' ${ }^{9}$ Toxicity bioassays can help us understand the biological effects of the compounds, its availability and interactions of the toxicants ${ }^{10}$. Out of various toxicity tests, phytotoxicity analysis using seed germination and root elongation is widely used for quick and accurate results. This test is simple, sensitive, cost effective and suitable for unstable chemicals in the sample ${ }^{11}$.

The present study helps to bring focus to the microbiological content and environmental implications of MSW leachates. It also provides a comparative view of degradability of leachate, based on aging. The treatment of the leachates has been carried out by CleanMaxx ANB (for anaerobic treatment) and CleanMaxx (for aerobic treatment). CleanMaxx ANB is a commercially available microbial consortium of facultative anaerobes specially chosen for their potential to breakdown complex organic contaminants in wastewater such as recalcitrant organic compounds and xenobiotic compounds. CleanMaxx consists of an array of versatile bacterial species which are capable of improving the physico-chemical parameters of effluents. The study highlights the efficiency of improvement in effluent parameters post microbial treatment with CleanMaxx ANB and CleanMaxx. Additionally, it also brings into focus the reduction in phytotoxicity of leachates post its biological treatment.

\section{Materials and Methods}

\subsection{Sampling}

The leachate samples were collected from MSW landfill site in Mumbai. The first set of samples was collected from an aged landfill site (old leachate) where the waste accumulation and degradation was carried out over a long period of time. Another set of sample of leachate were collected from a slightly fresher landfill site (fresh leachate) which was still being loaded with waste material on daily basis.

Multiple samples from each site were collected in 2 litre plastic bottles and pooled together to form representative samples.

\subsection{Anti microbial Assay}

The leachate samples collected from landfill sites were analyzed for presence of their antibacterial activity against four bacterial species by testing different concentrations of the leachate samples against culture strains of Bacillus subtilis ATCC 6633 (American Type Culture strain, Rockville, MD), Pseudomonas aeruginosa ATCC 25619, Escherichia coli ATCC 8739 and Staphylococcus aureus ATCC 6538 using agar well diffusion method ${ }^{12}$. The densities of all actively growing strains were adjusted to $10^{8}$ 
Colony Forming Units (CFU)/ml, further to which $100 \mu \mathrm{l}$ was seeded in $100 \mathrm{ml}$ molten Trypticase Soy Agar (TSA) (maintained at $60^{\circ} \mathrm{C}$ ). Wells of $6 \mathrm{~mm}$ diameter were bored into the seeded plates, and $40 \mu \mathrm{l}$ of leachate samples were loaded in increasing dilutions (undiluted sample, 1:2 and 1:5). Post loading, the samples were allowed to diffuse. Plates were incubated at $37^{\circ} \mathrm{C}$ for 24 hours before observations were recorded.

\subsection{Microbial Diversity Analysis}

The samples were tested for its microbial density and diversity using conventional plate count method ${ }^{13}$. For estimation of total microbial count of the leachate sample, $1 \mathrm{ml}$ of the sample was dispensed in $99 \mathrm{ml}$ of sterile phosphate buffer saline (Composition: $8 \mathrm{gm} / \mathrm{lit} \mathrm{NaCl}, 0.2 \mathrm{gm} /$ lit $\mathrm{KCl}, 0.2 \mathrm{gm} / \mathrm{lit} \mathrm{KH}_{2} \mathrm{PO}_{4}$ ) and finally adjusted to $\mathrm{pH}=$ $7.3 \pm 0.2$. This $10^{-2}$ suspension so prepared was subjected to serial dilution till $10^{-7}$ dilutions. For each of the last four dilutions, $0.1 \mathrm{ml}$ was spread onto TSA plates $(15 \mathrm{gm} / \mathrm{lit}$ casein enzymatic hydrolysate, $5 \mathrm{gm} / \mathrm{lit}$ sodium chloride, and $5 \mathrm{gm} /$ lit soya peptone with $2 \%$ agar) at $\mathrm{pH} 7.2 \pm 0.2$. All the plates were incubated at $35^{\circ} \mathrm{C}$ for 48 hours. CFU (Colony Forming Units) per $\mathrm{ml}$ for all the samples was calculated using the following formula:

\section{$C F U / m l=($ Number of colonies $x$ dilution factor $) /$ volume of culture spread onto the plate}

\subsection{Microbial Treatment of Leachate Samples}

Initially, 1 litre of old and fresh leachate were an aerobically treated after transferring to Schott Duran bottles. A microbial consortium based commercial product CleanMaxx ANB was added to both the leachate samples at the concentration of $5 \mathrm{~g} / \mathrm{L}$ and mixed properly. The bottles were kept in static condition to develop an anoxic environment and treatment continued till 7 days. Post anaerobic treatment, the samples were subjected to 7 days of aerobic treatment.

The anaerobically treated leachate samples were transferred to $2 \mathrm{~L}$ capacity measuring cylinders and microbial consortium based commercial product CleanMaxx was added at the concentration of $5 \mathrm{~g} / \mathrm{L}$. The system was subjected to aeration for the period of 7 days. After the completion of each treatment, physico-chemical properties viz. COD, ammoniacal nitrogen, colour, Total Dissolved Solids (TDS), Total Suspended Solids (TSS) and pH were estimated.

\subsection{COD Analysis}

Aliquots of each sample were withdrawn and filtered using a Whatman No. 1 filter paper. The samples were diluted using distilled water in the ratio of 1:10 from which $0.2 \mathrm{ml}$ of each diluted samples was added to the COD vial of high range (HR) and mixed by inverting them multiple times. The samples were digested in Hanna COD reactor (HI839800) for two hours at $150^{\circ} \mathrm{C}$. After the digestion was complete, the vials were removed carefully from the heating block and kept for cooling. The readings were recorded in Parts Per Million (PPM) by placing the vials in Hanna COD and Multiparameter photometer (Model HI83099) and measuring them against a blank vial.

\subsection{Ammoniacal Nitrogen Analysis}

Aliquots of filtered leachate samples were diluted in the ratio of 1:1000. Ten $\mathrm{ml}$ of the diluted sample was transferred to the cuvettes and adjusted as blank, the sample was further reacted with reagents from Hanna make ammoniacal nitrogen kit of Medium Range (MR), where 4 drops of reagent A (HI 93715A-0) was added followed by 4 drops of reagent $\mathrm{B}$ (HI 93715B-0). The solution was mixed and readings were recorded (in ppm) using Hanna COD and Multi-parameter photometer.

\subsection{Colour Analysis}

Aliquots of filtered leachate samples were diluted in the ratio 1:100. Ten $\mathrm{ml}$ of the diluted samples were transferred to clean cuvettes. Equal volume of distilled water was used as a blank. The readings were recorded and expressed in Platinum Cobalt Unit (PCU) using Hanna $\mathrm{COD}$ and Multi-parameter photometer.

\subsection{TDS and $\mathrm{pH}$ Estimation}

The leachate samples were diluted to 1:100 using distilled water. TDS meter probe was inserted into the diluted sample. The TDS and $\mathrm{pH}$ of the samples were estimated by selecting the $\mathrm{pH}$ and TDS estimation mode respectively and the readings were recorded.

\subsection{TSS Analysis}

Whatmann filter paper No. 1 was weighed in an analytical weighing balance. Leachate samples ( $25 \mathrm{ml}$ each) were passed through the pre-weighed Whatman filter papers using vacuum based filtering apparatus. The filters were 
dried in hot air oven at $110^{\circ} \mathrm{C}$ for 1 hour. The filters were cooled in a desiccator at room temperature and the final weight of the filter study was recorded using a analytical weighing balance. The TSS of the samples was calculated using the formula:

$$
\begin{aligned}
\text { TSS }(\mathrm{mg} / \mathrm{L})= & {[\text { Weight of the residue }(W) \text { in } \mathrm{mg} / \text { Volume }} \\
& \text { of sample }(\mathrm{V}) \text { in } \mathrm{ml})] \mathrm{X} 1000
\end{aligned}
$$

$W(m g)=W 2$ (weight of filter paper and residue in $\mathrm{mg})$ W1 (weight of clean filter paper in $\mathrm{mg}$ )

\subsection{Seed Germination Assay}

The phytotoxicity of untreated and treated leachate samples were analyzed using viable seeds of Cicer arietinum (Bengal gram).The seeds were soaked overnight in distilled water before sowing in garden soil. Each leachate sample was diluted in 1:1 ratio using distilled water and added to the potted soil after the seed was sown. Equal volume of leachate sample was added in case of each test seed. For the control set, the volume was compensated using distilled water. The trial was conducted at room temperature. Progress of seed germination was monitored on daily basis:

Percentage seed germination $=($ No. of germinated seeds $)$ Total number of planted seeds) $\times 100^{14}$

\subsection{Plant growth Parameters Analysis}

The germinated seedlings from the above assay were allowed to grow in the same pot for 10 days post germination. The root and shoot length was measured after 10 days. The statistical analysis of the study was performed using one way analysis of variance (ANOVA) test.

\section{Results and Discussion}

\subsection{Antimicrobial Bioassay}

In order to evaluate the microbial toxicity of the leachate against microorganisms due to the presence of inhibitory compounds, the leachate samples were subjected to a bioassay using the agar well diffusion method $^{13}$. The samples were tested against $B$. subtilis ATCC 6633, E. coli ATCC 8739, P. aeruginosa ATCC 25619 and S. aureus ATCC 6538. The leachate samples were assessed for their antimicrobial activity at neat, $1: 2$ and $1: 4$ dilutions.
No zone of inhibition was observed for all the dilutions of leachate samples. This indicates that leachate was safe to be treated using a microbial consortium and was not toxic to microorganisms in general. Thus, microbial toxicity assays could be implemented as a basic step to gauge the toxicity of the leachate before testing on higher life forms. A group of scientists assessed the toxicity of landfill leachate against fish species Clarias gariepinus where they found that the Median Lethal Dose $\left(\mathrm{LD}_{50}\right)$ of the leachate towards the fingerlings was $36.6 \%$ highlighting the toxic nature of the untreated leachate collected, indicative that the leachate could definitely be let into water bodies without treatment ${ }^{15}$. Thomas and Tyrell developed sensitivity assays using bioluminiscent bacteria to assess the toxicity of landfill leachate. They observed that the assays conducted on strains of Lemna minor and Thamnocephalus platyurus were most sensitive while that on Vibrio fischeri was the least ${ }^{16}$. Thus, antimicrobial testing could serve as a primary indicator of leachate toxicity as well as treatability.

\subsection{Total Microbial Count}

The samples showed presence of diverse microflora with a count of $4.8 \times 10^{6} \mathrm{CFU} / \mathrm{ml}$ and $6.9 \times 10^{7} \mathrm{CFU} /$ $\mathrm{ml}$ for old and fresh leachate samples respectively. This is in accordance with studies performed by Antai et al who found the microbial population in the selected leachate sample to be $19.6 \pm 1.88 \times 10^{7} \mathrm{CFU} / \mathrm{ml}^{17}$. The colonies that appeared revealed a diverse microbial population of both Gram natures. Some of the colonies observed were a variety of Bacillus sp., Pseudomonas sp., Klebsiella sp., E. coli, Salmonella sp., Vibrio sp. as well as certain other coliforms. In another study Oshode et al isolated 112 bacterial isolates belonging to 17 genera from the leachate sample they studied. They also found the presence of opportunistic pathogens as well as pathogens like Bacillus cereus, E. coli, Staphylococcus aureus, Clostridium sordelli, Clostridium perfingens and Salmonella arizonae in the leachate sample. The total microbial population ranged between $10^{6}$ to $10^{9} \mathrm{cfu}$ per $\mathrm{ml}$ of leachate sample. Several fungi such as Aspergillus spp., Fusarium oxysporum, Penicillum spp. and Rhizopus $s p$. were also found to be present $t^{15}$. Naveen et al analyzed the microbial population of landfill leachate and found to contain predominantly different kinds of Bacillus sp., Spirochetes and Vibrio $\mathrm{sp}^{18}$. 


\subsection{Bioremediation of Leachate Samples}

The leachate samples were subjected to microbial degradation in a two-step treatment process. Anaerobic treatment was followed by aerobic treatment in order to maximize degradation efficiency. Physico-chemical parameters at each stage were assessed as follows.

\subsection{COD Analysis}

The treatment of old leachate revealed that both the anaerobic and aerobic treatment contributed towards reducing the COD of the sample by $18.97 \%$ (Table 1 ). A similar trend was observed in treatment of the fresh leachate sample. However, it may be important to note that the percentage reduction of COD using aerobic treatment was nearly 2.8 times than that found in treated aged leachate reinstating the fact the biodegradable fraction in the fresh leachate is higher compared to the old leachate. Similarly, In a treatment of a closed landfill leachate samples, Brevibacillus panacihumi strain ZB1 was used in 42 day long coupled anaerobic-aerobic treatment, where they reported that high COD removal could be achieved by anaerobic treatment and it could be further enhanced by aerobic treatment, thereby improving overall efficiency $y^{4}$.

\section{$3.5 \mathrm{pH}$, TDS and TSS Analysis}

A slight shift in $\mathrm{pH}$ was observed from 8.2 to 7.5 in case of the old leachate (Table 1). The fresh leachate showed a pH shift from 6.6 to 7.2 (Table 2). In both cases, microbial intervention helped shift the $\mathrm{pH}$ towards neutral. The treatment of old leachate showed TDS reduction at both stages of the bioremediation process with a total reduction of $24.8 \%$. (Table1) In case of the fresh leachate, the reduction was $34.76 \%$ (Table 2). Surprisingly in the case of fresh leachate, the TDS reduction was mainly achieved using aerobic treatment, whereas for old leachate, the aerobic treatment helped in $24.05 \%$ reduction of TDS (Table 1).

The reduction in TSS of old leachate post anaerobic treatment was $9.8 \%$ and $24.05 \%$ (Table1) after the completion of aerobic treatment. In case of fresh leachate, anaerobic process helped in $18.5 \%$ reduction of the TSS of fresh leachate after which the aerobic treatment brought about a final reduction of $23.5 \%$ (Table 2). The reduction in TDS and TSS post microbial treatment process demonstrates the capability of microorganisms in bringing about a major impact on the amelioration of these physico-chemical parameters. Most studies rely on the use of chemical agents to alleviate high TDS and high TSS issues. For example, In a study conducted to understand the effect of perlite and bentonite on the physico-

Table 1. Effect on the Physico-chemical properties via microbial degradation of old leachate sample post anaerobic and aerobic treatment

\begin{tabular}{|l|l|l|l|l|l|l|}
\hline Sample & $\mathrm{pH}$ & $\begin{array}{l}\text { COD } \\
(\mathrm{PPM})\end{array}$ & $\begin{array}{l}\text { Ammoniacal } \\
\text { Nitrogen (PPM) }\end{array}$ & TDS (PPM) & $\begin{array}{l}\text { TSS } \\
(\mathrm{PPM})\end{array}$ & Colour(PCU) \\
\hline Raw old leachate & 8.2 & 31720 & 1334 & 5366 & 14860 & 4860 \\
\hline Anaerobically Treated old leachate & 7.9 & 29320 & 1346 & 4686 & 13400 & 3950 \\
\hline \% Reduction & & 7.56 & -0.89 & 12.67 & 9.8 & 18.72 \\
\hline Aerobically Treated old leachate & 7.5 & 25700 & 1030 & 4035 & 11285 & 3640 \\
\hline \% Reduction & & 18.97 & 22.78 & 24.8 & 24.05 & 25.01 \\
\hline
\end{tabular}

Table 2. Effect on the Physico-chemical properties via microbial degradation of fresh leachate sample post anaerobic and aerobic treatment

\begin{tabular}{|l|l|l|l|l|l|l|}
\hline Sample & $\mathrm{pH}$ & $\begin{array}{l}\text { COD } \\
(\mathrm{PPM})\end{array}$ & $\begin{array}{l}\text { Ammoniacal } \\
\text { Nitrogen (PPM) }\end{array}$ & TDS (PPM) & $\begin{array}{l}\text { TSS } \\
(\mathrm{PPM})\end{array}$ & Colour(PCU) \\
\hline Raw fresh leachate & 6.6 & 38610 & 1680 & 4435 & 10000 & 4250 \\
\hline Anaerobically treated fresh leachate & 6.1 & 33290 & 1672 & 4340 & 8150 & 3290 \\
\hline \% Reduction & & 13.78 & 0.4 & 2.1 & 18.5 & 22.58 \\
\hline Aerobically Treated fresh leachate & 7.2 & 17810 & 692 & 2893 & 7650 & 2790 \\
\hline \% Reduction & & 53.87 & 58.8 & 34.76 & 23.5 & 34.35 \\
\hline
\end{tabular}


chemical parameters of the leachate, it was observed that this treatment was successful in reducing the COD and BOD, but the TDS parameter was adversely affected with the increase in dissolved salts (present in the perlite and bentonite) that contributed to increase in the $\mathrm{TDS}^{19}$.

\subsection{Ammoniacal Nitrogen Analysis}

No reduction of ammoniacal nitrogen was seen in either leachate samples through the anaerobic process. The aerobic treatment of old leachate leads to an ammoniacal nitrogen reduction of $22.79 \%$. The fresh leachate showed a more heightened reduction of $58.8 \%$.

Zhang et al reviewed biological leachate treatment processes using bioreactors, where the ammoniacal nitrogen removal rate ranged between $66-97 \%$ highlighting the importance of an established microflora to optimize the parameter improvement in leachates ${ }^{20}$. However, most bioreactor systems utilize the indigenous microflora from the effluents to improve physico-chemical parameters. This may result in the increase of microbial species that may also be potential pathogens. It would therefore be advisable to utilize selected robust microbial strains in these bioreactors so as to discourage the growth on undesired organisms and accelerate the treatment process. Treatment of leachate with Brevibacillus panacihumi strain ZB1 showed a significant reduction in ammoniacal nitrogen. The anaerobic treatment (similar to our observations) did not improve due to the addition of the culture. However, the organism heightened the ammoniacal nitrogen removal from $15 \%$ (in control) to $52 \%$ (in treated) in the aerobic process ${ }^{4}$.

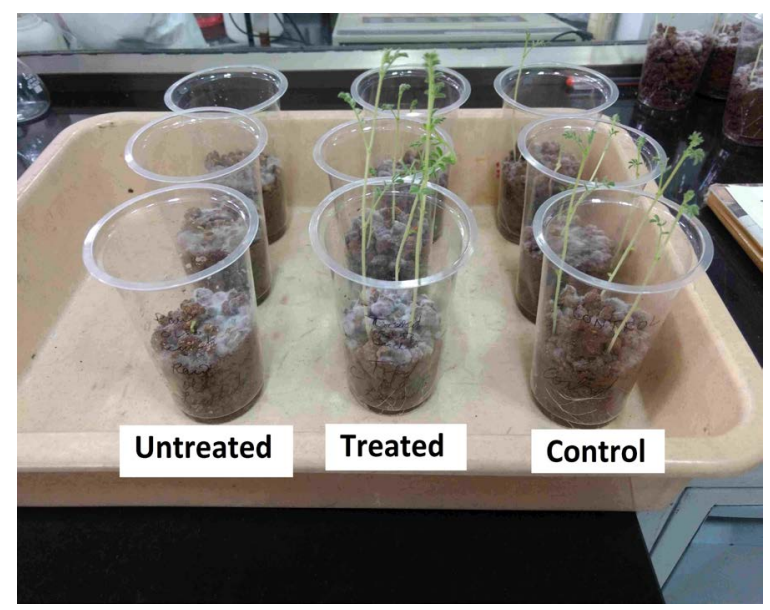

Figure 1. Observation for the growth of plants exposed to untreated and treated old leachate against control after 7 days of planting.

\subsection{Colour Reduction Analysis}

Both anaerobic and aerobic treatments contributed equally in reduction of the leachate colour. The final colour reduction achieved was $25 \%$ and $34 \%$ for the old and fresh leachates respectively. It can be noted that organisms contributing to both of these processes can metabolize different kinds of colour compounds that lead to more efficient reduction in overall leachate colour. This reinforces the importance of a multi-step treatment process to target different classes of compounds that need to be effectively degraded to create a cleaner leachate. The use of burnt pressmud was reported to be instrumental in reducing the colour of leachate by $35 \%{ }^{21}$. However the use of chemical adsorbents may also lead to bulking and a separate process of adsorbent removal may also have to be incorporated in the treatment process, thereby increasing the cost.

\subsection{Seed Germination Assay}

In order to evaluate whether the bioremediation of leachate helped in its phytotoxicity reduction, seed germination assay on Cicer arietinum (bengal gram) was carried out. Exposure of the seeds to untreated leachate affected the process of seed germination as shown in (Figure 1 and 2) indicating the presence of phytotoxic compounds. The control set showed an emergence of $88.88 \%$. Seeds exposed to the untreated old leachate showed delayed germination and led to only $11.11 \%$ emergence. The microbially treated old leachate showed a germination percentage of $88.88 \%$. The percentage germination of seeds exposed for untreated fresh leachate $(22.22 \%)$ was slightly better

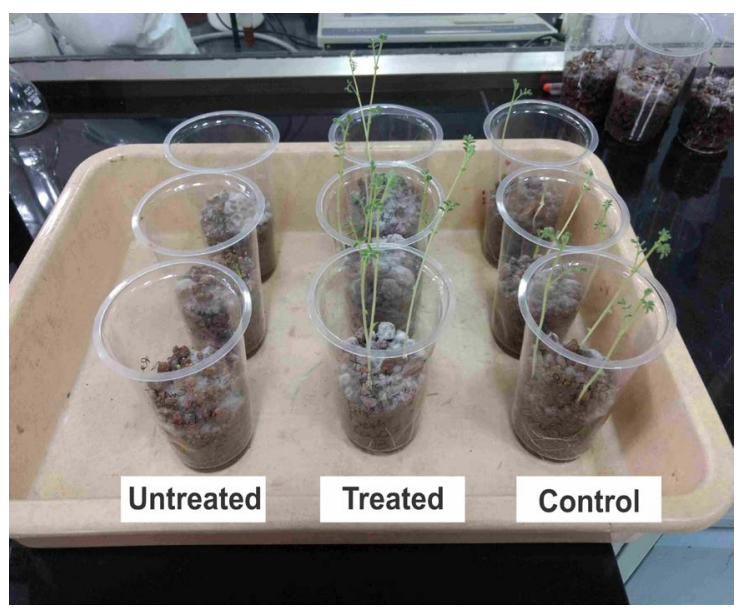

Figure 2. Observation for the growth of plants exposed to untreated and treated fresh leachate against control after seven days of planting. 
than that of the old leachate $(88.88 \%)$. Therefore, seed germination for microbially treated leachate samples was similar to the control. As per the recommendations of OECD (2006) and US EPA (1996) germination of seeds exposed to treat effluent samples should reach at least $70 \%$ and $90 \%$ respectively ${ }^{22}$.

In a study to assess the effect of landfill leachate on the germination of Cannabis sativa at varying concentrations (25\%, 50\%, $75 \%, 90 \%$ and $100 \%)$, it was observed that the toxic effect of the leachate on the seed increased in direct proportion to the concentration of leachate. The percentage germination of seeds exposed to increasing dilutions of the leachate ranged from 6.48 to $75.78 \%{ }^{23}$.

\subsection{Plant Growth Analysis}

The ability of a plant to assimilate nutrients from soil is a predisposing factor to the root and shoot length of the plant. The results were analyzed using ANOVA. No significant difference in root length was observed between the plants exposed to treated leachate samples and control set (Figure 3 and 4). The mean shoot length of the plants exposed to treated leachate samples was found to be higher than the control (Figure 3 and 4). A significant difference in growth of the plants that were exposed to untreated leachate samples was observed as compared to treated

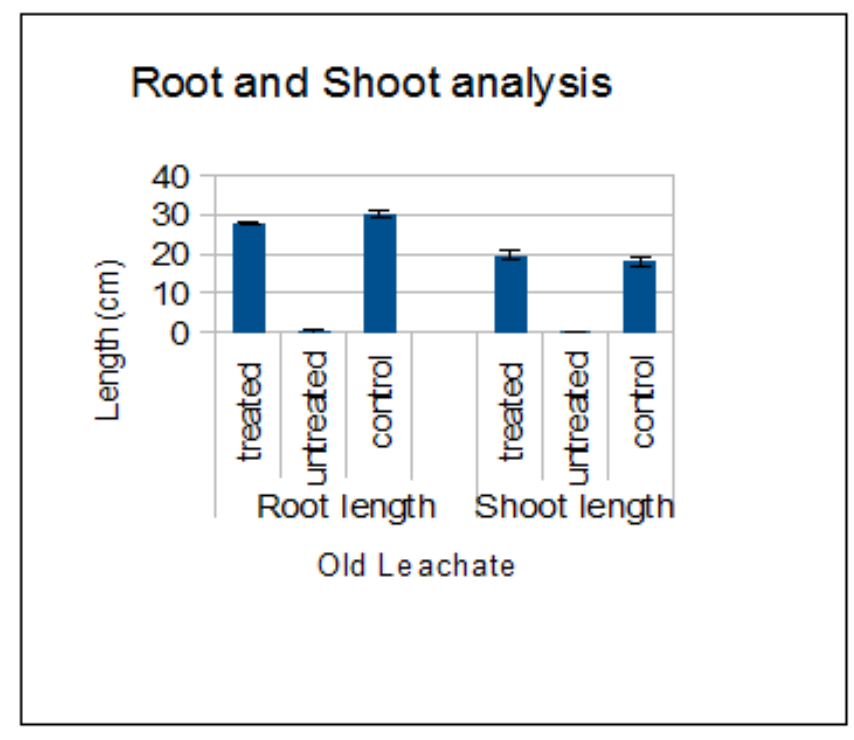

Figure 3. Comparison between root and shoot length for plants exposed to untreated and treated sample of old leachate against the control. and control set $(\mathrm{p}<0.05)$. The overall length of the plant exposed to treated fresh leachate was higher with the mean length of $51.2 \pm 3.56 \mathrm{~cm}$ as compared to the control having a mean length of $49.3 \pm 3.77 \mathrm{~cm}$. The molecules in the treated leachate may have contributed as a source of nutrients. It also meant that the treated leachate did not possess any constituents that could possibly be deleterious to the plants' growth. In case of the plants exposed to treated old leachate, the plant length was slightly lesser with a mean length of $47.7 \pm 4.21 \mathrm{~cm}$ as compared to the control which had a mean length of $49.3 \pm 3.77 \mathrm{~cm}$. This was indicative to the fact that there could be certain recalcitrant compounds that could not be degraded by the microbes that could have caused the slightly stunted growth. The effect of MSW leachate on the growth characteristics of Triticum aestivum (Bread wheat) was studied by one group. Contrary to our findings, they observed that plants treated with higher concentrations of leachate (75\% and $100 \%)$ showed better growth $(2.5 \%$ and $6 \%)$ and $100 \%$ survival as compared to control. However, lower concentrations of leachate showed higher shoot weight $(0.028$ and $0.030 \mathrm{gm})$ and chlorophyll content (213\% and $230 \%)$. It must be noted that some symptoms of stress like discoloration of leaf blade, wilting and yellowing of plants were also observed in plants, which were attributed to high salt concentration in the leachate ${ }^{24}$.

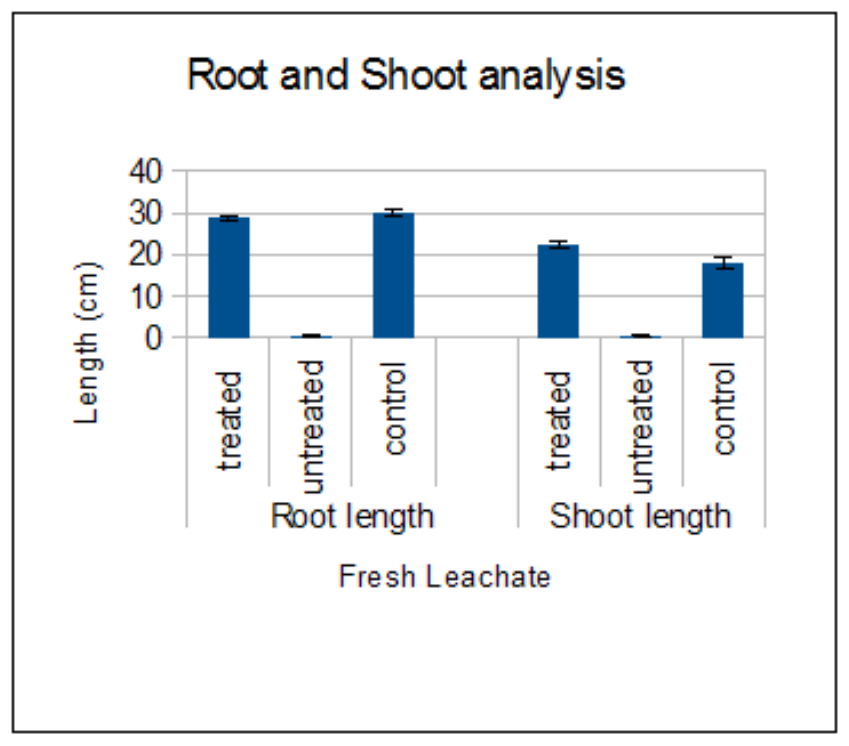

Figure 4. Comparison of root and shoot length between plants exposed to untreated and treated sample of Fresh leachate against the control. 


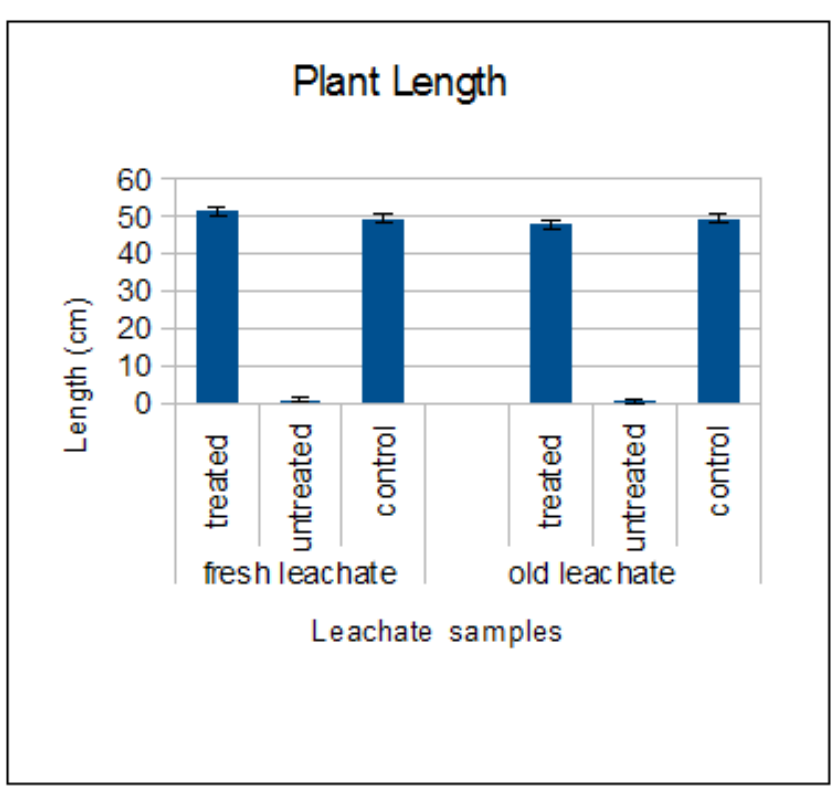

Figure 5. Comparison for the growth of plants exposed to untreated and treated sample of fresh and old leachate against the control.

\section{Conclusion}

The present study was conducted to evaluate the microbial diversity of the landfill leachate, and to assess the degree of improvement in the leachate (in terms of phytotoxicity) via bioremediation. The study also brought to light the necessity to treat fresh leachate as its capacity to be remediated decreases with ageing. A two-step treatment using commercially available products CleanMaxx ANB and CleanMaxx, were successful in reducing the COD, colour, ammoniacal nitrogen, TDS and TSS simultaneously. The degree of phytotoxicity reduction was demonstrated through the seed germination assay and plant growth analysis of Cicer arietinum. The significant improvement in physico-chemical properties and reduction in phytotoxicity points us towards concluding that the microbial remediation of landfill leachate is necessary to reduce the contamination of surrounding top soil and groundwater tables. Microbially treated leachate could then very well be followed by phytoremediation due to the alleviation of its phytotoxicity.

\section{Acknowledgement}

The authors would like to thank the employees of Organica Biotech Pvt. Ltd. for their support during the execution of this project.

\section{Reference}

1. Troschinetz AM, Mihelcic JR. Sustainable recycling of municipal solid waste in developing countries, Waste Management. 2009; 29:915-23. https://doi.org/10.1016/j. wasman.2008.04.016. PMid:18657963.

2. Kumar S, Bhattacharyya JK, Vaidya AN, Chakrabarti T, Devotta S, Akolkar AB. Assessment of the status of municipal solid waste management in metro cities, state capitals, class I cities, and class II towns in India: An insight, Waste Management. 2009; 29:883-95. https://doi.org/10.1016/j. wasman.2008.04.011. PMid:18595684.

3. Singh A, Zaidi J, Bajpai D, Sharma G, Yadav A, Chauhan DS, Ganesh S. Municipal solid waste management challenges and health riskproblematic solutions at Agra city, Advances in Applied Science Research. 2014; 5(3):397-403.

4. Er XY, Seow TW, Lim CK, Ibrahim Z and Mat Sarip SH. Biological treatment of closed landfill lea-chate treatment by using Brevibacillus panacihumi strain ZB1, IOP Conf. Series: Earth and Envi-ronmental Science. 2018; 40:1-12. https://doi.org/10.1088/1755-1315/140/1/012012.

5. Chatterjee N, Flury M, Hinman C, Cogger CG. Chemical and Physical Characteristics of Compost Leachates. Date accessed: 2013. https://www.wsdot.wa.gov/research/reports/ fullreports/819.1.pdf.

6. Peter K, Morton AB, Alix PR, Anders B, Anna L, Thomas HC. Present and long-term composition of MSW landfill leachate: A Review, Critical Reviews in Environmental Science and Technology. 2002; 32(4):297-336. https://doi. org/10.1080/10643380290813462.

7. Liu S. Landfill leachate treatment methods and evaluation of Hedeskoga and Måsalycke landfills. Date accessed: 2013. https://www.semanticscholar.org/paper/Landfill-leachatetreatment-methods-and-evaluation-Liu/8c3alf9e768fd61f 599375e3d2dd3c69a7273c7a.

8. Stegmann R, Heyer KU, Cossu R. Leachate Landfill Treatment. Date accessed: 2005. http://www.ifas-hamburg. com/PDF/leachate05.pdf.

9. Zaltauskaite J, Vaitonyte I. Toxicological assessment of closed municipal solid-waste landfill impact on the environment, Journal Environmental Research, Engineering and Management. 2016; 72(4):8-16. https://doi.org/10.5755/j01.erem.72.4.16555.

10. Zaltauskaite J, Cypaite A. Assessment of landfill leachate toxicity using higher plants, Environmental Research, Engineering and Management. 2008; 4:42-47.

11. Wang X, Sun C, Gao S, Wang L, Shuokui H. Validation of germination rate and root elongation as indicator to assess phytotoxicity with Cucumis sativus, Chemosphere. 2001; 44(8):1711-21. https://doi.org/10.1016/S0045-6535(00)00520-8.

12. Balouiri M, Sadiki M, Ibnsouda SK. Methods for in vitro evaluating antimicrobial activity: A review, Journal of 
Pharmaceutical Analysis. 2016; 6(2):71-79. https:// doi.org/10.1016/j.jpha.2015.11.005. PMid:29403965 PMCid:PMC5762448.

13. Bacteriological Analytical Manual. Date accessed: 2018. https://www.fda.gov/food/laboratory-methods-food/bacteriological-analytical-manual-bam.

14. Amin H, Arain BA, Amin F, Surhio MA. Phytotoxicity of chromium on germination, growth and biochemical attributes of Hibiscus esculentus L, American Journal of Plant Sciences. 2013; 4:2431-39. https://doi.org/10.4236/ ajps.2013.412302.

15. Oshode OA, Bakare AA, Adeogun AO, Efuntoye MO, Sowunmi AA. Ecotoxicological assessment using Clarias Gariepinus and Microbial Characterization of Leachate from municipal solid waste landfill, International Journal of Environmental Research. 2008; 2(4):391-400.

16. Thomas DJ, Tyrell SF, Smith R, Farrow S. Bioassay for the evaluation of landfill leachate toxicity, Journal of Toxicology and Environmental Health - Part B: Critical. 2009; 12(1):83-105. https://doi. org/10.1080/10937400802545292. PMid:19117211.

17. Antai SP, Louis OI, Tiku DR. Microbiological and physicochemical analysis of some selected mu-nicipal dumpsites in calabar municipality, Cross River State, Imperial Journal of Interdisciplinary Research. 2016; 2(11):1463-77.

18. Naveen BP, Mahapatra DM, Sitharam TG, Sivapullaiah PV, Ramachandra TV. Physico-chemical and biological characterization of urban municipal landfill leachate,
Environmental Pollution. 2016; 20:1-12. https://doi. org/10.1016/j.envpol.2016.09.002. PMid:27616651.

19. Raghab SM, Meguid AMAE, Hegazi HA. Treatment of leachate from municipal solid waste landfill, HBRC Journal. 2013; 9:187-92. https://doi.org/10.1016/j.hbrcj.2013.05.007.

20. Zhang D. Microbes in biological processes for municipal landfill leachate treatment: Community, function and interaction, International Biodeterioration and Biodegradation. 2016; 113:88-96. https://doi.org/10.1016/j. ibiod.2016.02.013.

21. Azme NNM, Murshed MF. Treatability of stabilize landfill leachate by using pressmud ash as an ad-sorbent, IOP Conf. Series: Earth and Environmental Science. 2018; 140:12-41. https://doi.org/10.1088/1755-1315/140/1/012041.

22. Parus A, Wojciechowska A, Wojciechowska I. Phytotoxicity of pyridineamidoximes against two crop plants: Preliminary evaluation, Polish Journal of Agronomy. 2016; 24:16-22. https://doi.org/10.14504/ar.16.6.1.

23. Vaverkova MD, Zloch J, Adamcova D, Radziemska M, Vyhnanek T, Trojan V • Winkler J, Dordevic B, Jakub Elbl J, Martin Brtnicky M (2017) Landfill Leachate Effects on Germination and Seedling Growth of Hemp Cultivars (Cannabis Sativa L.) Waste Biomass Valor 10.1007/s12649017-0058-z.

24. Suman Mor S, Kamalpreet Kaur K, Ravindra Khaiwal R. Growth behavior studies of bread wheat plant exposed to municipal landfill leachate, Journal of Environmental Biology. 2013; 34:1083-87. 